\section{British Society for Digestive Endoscopy}

The spring meeting of the British Society for Digestive Endoscopy was held at Harrogate on 13-15 February 1975. It was a new venture and included two days devoted to teaching endoscopy. Over 100 attended on each day. The first day dealt with the basic technique of upper gastrointestinal endoscopy, and the second with ERCP and colonoscopy. Generous support from the pharmaceutical industry and instrument manufacturers enabled models and tape/slide machines to be available for teaching in small groups.

The final day was devoted to the spring meeting of the Society, and included six free papers, abstracts of which are published below, and a symposium on 'Growing points in endoscopy'.

\section{Bleeding oesophagitis due to enforced recumbency}

A. REUBEN, J. DILAWARI, AND P. B. COTTON (Department of Gastroenterology, The Middlesex Hospital, London) The more frequent use of urgent endoscopy ${ }^{1}$ in the investigation of patients with gastrointestinal bleeding has shown that acute oesophagitis is a more frequent cause than had been believed hitherto. ${ }^{2}$ We present our findings in a selected group of five patients, each of whom was undergoing treatment in hospital for an unrelated condition, and who then presented with haematemesis and/or melaena, or recurrent severe unexplained anaemia. In each patient the clinical situation was such that erosions or ulcers induced by stress or drugs might be expected as the cause of bleeding. Barium studies were unhelpful in all patients, but each had severe haemorrhagic oesophagitis at endoscopy. Institution of simple medical therapy led to the prompt cessation of bleeding. The common feature in all patients was enforced recumbency, due to severe neurological disease, rheumatic disorders, or following general surgical or orthopaedic procedures. In retrospect, a history of oesophageal reflux was often obtained, indicating that earlier recognition of the condition might allow simple and effective prophylaxis.
References

${ }^{1}$ Cotton, P. B., Rosenberg, M. T., Waldram, R. P., and Axon, A. T. R. (1973). Early endoscopy of oesophagus, stomach, and duodenal bulb in patients with haematemesis and melaena. Brit. med. J., 2, 505.

2Jones, F. Avery, Gummer, J. W. P., and LennardJones, J. E. (1968). In Clinical Gastroenterology, p. 548. Blackwell, Oxford.

Multiple persisting idiopathic gastric erosions

W. A. F. MCADAM, A. G. MORGAN, A JACKSON, J. N. GLANVILLE, AND G. CHANDLER (St James' Hospital, Leeds) During the past 18 months, three patients endoscoped because of a bariumnegative dyspepsia were found to have multiple small acute-looking gastric erosions. Each patient had between 20 and 30 erosions, on an average between 2 and $3 \mathrm{~mm}$ in diameter. In two patients, the erosions encircled the pylorus, but in the third they were limited to the body of the stomach. Biopsy of the surrounding gastric mucosa was normal and showed no evidence of gastritis. No aetiological factors could be determined. The patients were on no drug therapy known to cause gastric erosions. Virology studies, including virus culture and electron microscopy of the gastric biopsy and faeces, together with blood agglutination levels, are being done. In two patients, conventional treatment for gastric ulceration has been tried, including Biogastrone, Caved-S, DeNol, and antacids without success. In one patient, after 12 months of severe dyspeptic symptoms and continuing positive endoscopic findings, a highly selective vagotomy was performed. Although the patient still has mild dyspepsia, no recurrence of the gastric erosion has been seen on endoscopy. This paper is presented in an endeavour to find out if members of this Society have seen similar patients, and to ask for suggestions as to a possible approach to treatment.

Measurement of gastric mucosal potential difference at endoscopy

A. HOSSENBOCUS, P. FITZPATRICK, AND D. G. COLIN-JONES (Southampton General Hospital, Southampton) There is a potential difference (pd) across the gastric mucosa, the luminal aspect being negative with respect to the serosal aspect. Andersson and Grossman (1965) found the pd to be $-44 \mathrm{mV}$ in the body of the stomach, $-35 \mathrm{mV}$ in the antrum, $-7 \mathrm{mV}$ in the duodenal bulb, and $-15 \mathrm{mV}$ in the oesophagus. In this study, similar results were found in 14 subjects when conven $\overrightarrow{\bar{F}}$ tional techniques were used. In a furthe 25 subjects, the pd in the duodenal bulbf and at five sites in the stomach wasn measured under direct vision during diagnostic endoscopy by passing an ex 2 ploring electrode through the biopsets channel of the GIFD Olympus endoscope? Biopsies were subsequently taken from those sites. Technically satisfactory results were obtained in 22 cases. In four of those, there was obvious bile reflux int\& the stomach during the procedure. The remaining 18 subjects were divided on the basis of histology into two groups, one with significant gastritis on the lesser curve (six subjects) and one with normaf lesser curve mucosa (12 subjects). In the normal group, pd was much lower in the antrum than at the high greater curve. $\mathrm{An}^{3}$ unexpected finding was that it was in $<$ variably lower at the high lesser curve $\overrightarrow{0}$ $-15.8 \pm 2.2 \mathrm{mV}$ (mean $\pm \mathrm{SE}$ ) than â the high greater curve, $-37 \cdot 3 \pm 2.0 \mathrm{mV}^{\text {? }}$ The group with gastritis had a significantlyo lower $(\mathrm{P}<0.01) \mathrm{pd}$ at the high lesser curve, $-4.8+0.5 \mathrm{mV}$, than the normab group. The four subjects with bile refluxo all had low potential differences as expected. This study confirms previous $\Rightarrow$ impressions that gastritis is associated with a lowered potential difference. Furthermore, the finding of a lowered potential difference in the antrum and on the lesser curve, even in the normale stomach, is of theoretical interest in viewof the known predilection of gastric ulcers 3 for those areas.

Reference

Andersson, S., and Grossman, M. I. (1965). Profile음 of $\mathrm{pH}$, pressure and potential difference at the gastrodeuodenal junction in man.음 Gastroenterology, 49, 364-371.

Benign gastric ulcer-An endoscopic survey

G. K. T. HOLMES AND R. COCKEL (Selly Oak Hospital, Birmingham) Previous studies of the clinical features of peptic ulceration have been based largely on lesions recognized radiographically. ${ }^{1} \mathrm{Re}-{ }^{-}$ cent developments in fibreoptic endoscopy $\frac{T}{\circ}$ have improved diagnostic accuracy allow- $\frac{\vec{D}}{\vec{D}}$ ing assessment from a more certain view- $\stackrel{\square}{\triangle}$ point. We have reviewed the clinical $\stackrel{\mathbb{Q}}{\varrho}$ features of 100 consecutive patients with benign gastric ulceration seen during upper gastrointestinal panendoscopy. In-O dications for endoscopy were doubtfule radiographic findings $(35 \%)$, acute gastrointestinal haemorrhage $(32 \%)$, pain $(35 \%)$, 
weight loss $(10 \%)$, and confirmation of ulcers seen radiologically $(8 \%)$. Twothirds of all patients were male. Pain was epigastric in $77 \%$, diffuse abdominal in $11 \%$ and nocturnal in $50 \%$. Eight per cent had no pain, $57 \%$ reported vomiting, and $39 \%$ weight loss. In contrast with earlier series $48 \%$ of the ulcers were located high on the lesser curve. Half were between 1 and $3 \mathrm{~cm}$ in diameter. Multiple ulcers were found in nine patients and an associated duodenal ulcer in only three. ${ }^{2}$ Elderly patients were more likely to have high lesser curve ulceration and present with haemorrhage. Younger patients more often had distal ulcers and presented with pain; haemorrhage was rare. Anaemia $(\mathrm{Hb}<13 \mathrm{~g}$ in men $<12 \mathrm{~g}$ in women) was present in $80 \%$ of males and $92 \%$ of females who had bled acutely. Otherwise, except for one woman with a haemoglobin of $11.6 \mathrm{~g}$, anaemia indicated a second diagnosis. Treatment was initially medical in $83 \%$ and surgical in $17 \%$; after one year a further $15 \%$ had required operation. Four patients died during the limited follow-up period, one following surgery for haemorrhage, two with congestive cardiac failure associated with carbenoxolone therapy, and one from bronchopneumonia five months after endoscopy.

\section{References}

${ }^{1}$ Sun, D. C. H., and Stempien, S. J. (1971). Gastroenterology, 61, 576-584.

${ }^{2}$ Rumball, J. M. (1971). Gastroenterology, 61, 622-627.

A comparative study of the diagnostic value of upper gastrointestinal endoscopy and radiology

B. MOULE, K. M. COCHRANE, G. S. SOKHI, R. I. RUSSELL, AND L. H. BLUMGART (University Department of Surgery and Departments of Radiology and Gastroenterology, Glasgow Royal Infirmary) A prospective study was conducted to compare the diagnostic accuracy of oesophagogastroduodenoscopy and barium meal examination. In the initial phase of the study (study I) all patients were investigated by a standard barium meal. The indications for endoscopy were equivocal findings on barium meal, $x$-ray negative dyspepsia, or suspected recurrent ulceration. In addition all cases of suspected gastric ulcer and gastric carcinoma were examined to confirm the $x$-ray findings and obtain histology. In the second study (study II) endoscopy was carried out following a routine barium meal and the patient was then referred for a second double contrast barium study, the radiologist being in ignorance of both the initial barium meal findings and the endoscopic findings.

\section{STUDY I}

One hundred and ninety-seven patients were examined. Of these 130 had equivocal or abnormal barium meal studies, 40 had $x$-ray-negative persistent dyspepsia, and 19 had had previous gastric surgery. There was a disagreement of $49 \%$ between the radiological and endoscopic findings. This figure is higher than that reported by others (McColl, 1972; Salmon et al, 1972; Cotton, 1973). The disagreement between radiology and endoscopy was highest in differentiating gastric ulcer from gastric carcinoma and in this situation the radiological evidence was erroneous in $46 \%$. Endoscopic examination led to a change in diagnostic decision in 94 patients and as a result operation was dictated in 19 cases and laparotomy was considered to be averted in 40 patients.

\section{STUDY II}

This survey consisted of 19 patients. The findings of the double-contrast barium meal performed by a single radiologist, who was in ignorance of the endoscopic findings, revealed that there was an overall agreement of opinion in 16 of the 19 cases $(84 \%)$ although in three cases gastric erosions were seen at endoscopy in patients with a normal barium meal. In three patients there was disagreement, a gastric ulcer failing to show up on barium meal in one patient and in two patients a radiological diagnosis suggestive of gastric ulcer or gastric carcinoma was not substantiated by the endoscopic findings. A change in management was therefore dictated by endoscopy in only three instances. It is concluded that the large discrepancy between endoscopic and radiological studies reported from many centres can be reduced very considerably by the use of expert radiological opinion based on double contrast barium methods.

\section{References}

Cotton, P. B. (1973). Brit. med. J., 2, 161-165.

McColl, I. (1972). Brit. J. Surg., 59, 793-794.

Salmon, P. R., Brown, P., Htut, T., and Read, A. E. (1972). Gut, 13, 170-175.

\section{Oesophageal dilatation using the Eder- Puestow dilators}

C. M. S. ROYSTON, B. L. DOWLING, AND M. J. GEAR (Gloucester Royal Hospital) In recent years the role of the fibreoptic endoscope as a diagnostic tool has become firmly established. The potential of these new instruments for therapeutic purposes is becoming realized more slowly. One such use is for dilatation of oesophageal strictures in conjunction with EderPeustow dilators. This method of dilatation has the following advantages: it is safer, it can be performed without general anaesthesia on an outpatient basis, and finally it can be used in almost any patient, eg, patients with severe kyphosis, where rigid endoscopy is impossible. We have performed 51 dilatations on 26 patients. The ages ranged from 45 to 89 (mean age 68). The maximum number of dilatations performed in one patient is five. The majority of dilatations were performed for stricture secondary to a hiatus hernia. The only complication we have had is a single case of aspiration pneumonia; no perforations have occurred. By using the Eder-Peustow dilators we have been able to adopt a more conservative surgical approach to patients with tight oesophageal strictures secondary to oesophagitis, thus avoiding the hazards of transthoracic surgery. We have treated eight patients with preoperative dilatation followed by transabdominal repair of the hiatus hernia. In two of these patients postoperative dilatation was necessary on one occasion, but in the remainder no further treatment was required. 